\title{
The dilemma of physician shortage and international recruitment in Canada
}

\section{Nazrul Islam*}

\begin{abstract}
The perception of physician shortage in Canada is widespread. Absolute shortages and relative discrepancies, both specialty-wise and in urban-rural distribution, have been a daunting policy challenge. International Medical Graduates (IMGs) have been at the core of mitigating this problem, especially as long as shortage of physicians in rural areas is concerned. Considering such recruitment as historical reality is naive annotation, but when it is recommended per se, then the indication of interest overweighs the intent of ethically justified solution. Such a recommendation has not only invited policy debate and disagreement, but has also raised serious ethical concerns. Canadian healthcare policymakers were put into a series of twisting puzzles-recruiting IMGs in mitigating physician shortage was questioned by lack of vision for Canada's self-sufficiency. In-migration of IMGs was largely attributed to Canada's point-based physician-friendly immigration system without much emphasizing on IMGs' home countries' unfavorable factors and ignoring their basic human rights and choice of livelihood. While policy-makers' excellence in integrating the alreadymigrated IMGs into the Canadian healthcare is cautiously appraised, its logical consequence in passively drawing more IMGs is loudly criticised. Even the passive recruitment of IMGs raised the ethical concern of source countries' (which are often developing countries with already-compromised healthcare system) vulnerability. The current paper offers critical insights juxtaposing all these seemingly conflicting ideas and interests within the scope of national and transnational instruments.

Keywords: Physician Shortage, Canada, International Recruitment, Ethical Concern, International Medical Graduates (IMGs)

Copyright: @ 2014 by Kerman University of Medical Sciences

Citation: Islam N. The Dilemma of physician shortage and international recruitment in Canada. Int J Health Policy Manag 2014; 3: 29-32. doi: 10.15171/ijhpm.2014.53
\end{abstract}

Article History:

Received: 16 May 2014 Accepted: 28 May 2014 ePublished: 29 May 2014

\section{Correspondence to:}

Nazrul Islam

Email: nazrul.islam@ubc.ca

\section{Background}

Canada ranks $26^{\text {th }}$ among 34 developed countries in terms of physician-to-population ratio; this ratio (per 1,000 population) in Canada is 2.4 (2.03 when excluding medical residents) while the Organization for Economic Co-operation and Development (OECD) average is $3.1(1,2)$. A 2010 estimate indicates that about $6.6 \%$ of Canadians aged 12 and older reported being unable to find a regular physician (3). In 2011, 15.3\% Canadians reported being without a Family Physician (4). Mitigating such a crucial problem lies at the core of all discussions on Canada's unmet healthcare need (3). Canada's physician-to-population ratio was one of the highest in the early 1970s. Consequently, Barer-Stoddart report suggested to cut down enrolment in medical schools, and to decrease recruitment of International Medical Graduates (IMGs) $(3,5-7)$. Consequently, Canada experienced a huge shortage of physicians, and the perception of shortage is widespread till date despite an increase of over $60 \%$ in medical school enrolment (8). Canada's physician shortage is principally attributed to: policy changes leading to a reduction in the enrolment at Canadian medical schools, restrictions on foreign doctor recruitment, emigration of Canadian physicians to the United States (US), mal-distribution of physicians both geographically and specialty-wise, aging physicians, changes in population demographics, and feminization of physician workforce among others (3,9-12).

\section{Existing policy recommendations}

Policy recommendations to mitigate the physician shortage emphasize on increasing enrolment at medical schools, improving the distribution of physicians in urban and rural areas and across the specialties, and recruitment of IMGs. Canada has lately started increasing medical school enrolment $(3,8)$; however, the shortage of physicians in rural communities is a significant concern. About $20 \%$ of Canadians live in rural areas, while less than $10 \%$ of the physicians practise in rural Canada. This scenario is even worse in terms of specialists' service; only $2 \%$ of specialists serve in rural areas (1). This is crucial because recruitment of IMGs comes into play to fill-in this gap in physician supply. Currently, IMGs constitute about one-fourth of the total physician workforce in Canada (1), and it has been projected that Canadian physician-to-population ratio will decline by 2020 without a significant recruitment of IMGs (3,13-15).

Pros and cons: policy puzzle and ethical concern

First of all, global trend shows that recruitment of IMGs is nothing new; nor is it unique to/in Canadian context. As stated above, IMGs have been being recruited mostly to meet the shortage in the rural physician workforce. If 
such information is presented as a historical reality, this is merely a naïve statistical data or statement. However, when it is recommended per se, then the indication of interest overweighs the intent of ethically justified solution.

The major policy argument encompassing ethical aspects of such recruitment arises with the shifting paradigm of IMG mobilization (16). The top two 'source' countries of IMGs in the 1970s-United Kingdom (UK) and Ireland-have been replaced by South Africa and India $(5,16,17)$. Parenthetically, the AIDS epidemic in South Africa has largely been attributed to a severe shortage of physicians due to 'brain drain' to developed countries including Canada and has fuelled global debates about whether it is ethically justified to recruit IMGs from countries which themselves are suffering from acute shortage of trained physicians $(13,17,18)$.

Further to this, in-migration of IMGs to Canada (and any other countries) is a multifaceted phenomenon. Several 'push' factors in source countries (e.g., dangerous working and living environment, lack of effective workplace support and compensation, overall poor living conditions) and 'pull' factors in recipient countries such as Canada (e.g., enhanced quality of life, improved working conditions, safety) have been identified in affecting the IMGs migration (19).

Again, IMGs may choose to leave their countries of origin to work and settle in Canada for a perceived better life, wage and security. It is also cost-effective to recruit IMGs to fill-in the unmet need of Canadian healthcare, especially in rural areas (20). The former is not considered an ethical concern as it is IMGs' basic human right and personal autonomy to choose where to work at, but the latter is. The policy puzzle here is whether the recruitment is 'active' or 'passive', without clear definitions of either $(17,19)$.

In this context, the World Health Organization (WHO) formulated the Global Code of Practice for International Recruitment of Health Personnel, to emphasize the critical importance of the rights, obligations and expectations of source countries, destination countries and migrant health personnel $(13,17)$. Moreover, the Melbourne Manifesto attributes international recruitment to the source countries' inability in satisfying their own workforce needs and hence emphasizes on 'ethical recruitment policies' (17). Similarly, Commonwealth Ministers of Health approved the Commonwealth Code of Practice for International Recruitment of Health Workers in $2003(17,21)$. These are some of the overarching transnational instruments guiding Canada to make the recruitment process fair and ethical. Canada also recommended some guiding principles in line with the WHO Global Code emphasising on self-sufficiency, and mutual benefits to the participating parties without discrimination (17). But Canada's existing nation-wide instrument itself is not quite compatible in formulating a pan-Canadian effort to meet these recommendations. First of all, the Government of Canada, per se, does not recruit any healthcare professionals, be it domestic or international. On the other hand, it has "no authority over the actions of regional authorities or individual institutions in terms of ensuring their compliances" (19). Although the Federal Ministry of Health could have responded to these 'global' codes, their implementation lies exclusively at the provincial/regional level $(14,17,19)$. The ethical concern is manifold. Since Canadian immigration policy, like that of many other developed nations, explicitly welcomes 'skilled' immigrants, it cannot specifically restrict physicians or it also will then have to restrict people with training in other skilled categories (e.g., engineers, scientists). If Canada accepts refugees to help them improve their lives, how can it reject physicians from a poor country in improving their standards of living? (20)

Canada and other major IMGs-receiving countries, i.e., US, UK, Australia, have strongly emphasised increasing their medical school enrolment and thus attaining selfsufficiency (16). However, none has yet been successful in making physicians available in underserved rural areas, which is correctly identified as the major reason for IMGs recruitment, be it active or passive. While Canada has not been explicitly involved with 'active' recruitment from underdeveloped countries, it still requires IMGs to serve the rural underserved areas.

This is simply the statistical part of the scenario. Even if we assume that Canada can in no way be considered responsible for 'active' recruitment of IMGs (i.e., if we assume that Canada is recruiting IMGs only 'passively', and hence is beyond the scope of ethical concern) the following inevitable policy concern will arise surrounding the permanent/long term solution of the problem-in other words, 'self-sufficiency'. A study by Audas and colleagues (22) that tracked the movement of IMGs shows that they serve in rural areas for the duration of the service contract they are compelled to and then migrate to urban areas. Such findings not only imply the long-term failure of (even passive) recruitment of IMGs in mitigating the rural discrepancy in physician distribution, they also mandate policy reforms targeting self-sufficiency from within.

\section{Discussion and recommendations}

While physician shortage is a significant part of Canadian healthcare policy, proper physician distribution and hence ensuring efficiency is something equally emphasized. It has been argued that a higher physician-to-population ratio does not necessarily guarantee a better healthcare. Compared to Canada, Australia and France are performing pretty well with a higher physician-population ratio. However, Germany and Denmark, for example, have similar or worse avoidable mortality with more physicians, while Japan is doing better with fewer physicians (23).

However, there is consensus that Canada should increase the enrolment at medical schools. But, should Canada stop recruiting IMGs altogether? Before attempting to solve this crucial policy puzzle, let us solve its counterpart: Are there any viable (evident) alternatives to this problem? Possibly. It is suggested that Canada should meet the physician shortage by increasing enrolment at medical schools. It should also formulate an extensive plan to have physicians distributed in different specialities to deal with unmet need in light of the fact that, amid widespread perception of physician shortage, $16 \%$ of new specialist and sub-specialist physicians reported unemployment in a 2013 report published by the Royal College of Physicians and Surgeons of Canada (24). 
Possibly the major challenge will be to meet discrepancies in rural areas. To address this historic challenge, a handful of Canadian Universities introduced distributed medical education centers (such as, Northern Ontario School of Medicine, University of British Columbia's Northern Medical Program in Prince George, University of Sherbrooke's campus in Moncton, NB, and Dalhousie Medicine New Brunswick program in St. John) at rural/satellite campuses, and recent studies, premature however, showed promising outcomes in the retention of physicians in rural areas (25). However, Canada has much to learn from other countries which have succeeded in this field. For example, like Australia, Canada can incorporate rural retention policy in the medical curricula, offer more funding and scholarship opportunities for rural health, and more incentives and provisions for students from rural areas etc. (16).

What might, then, be the guiding principle for Canada in terms of recruiting IMGs? Canada can possibly learn from the UK in this context. The UK changed their policy to make it harder to recruit IMGs from developing worlds (26). Moreover, they have also developed a list of countries defined as developing worlds whereby recruitment is 'off-limit' (19). The next task will be to define active recruitment. While there is no operational definition of active recruitment in Canada, there is one from the UK's Department of Health Code of Practice. They define active recruitment as: "advertising employment opportunities within the UK healthcare sector and then acting in such a manner as to secure employment for that individual" (19).

Moreover, Canada should address the factors influencing its own physicians to migrate, especially to the United States, and attempt to repatriate them. Canadian students studying medicine abroad are also considered IMGs. The number of these Canadian IMGs has been estimated to have doubled since 2006 (when it was estimated to be around 1,500), which would expectedly pose a significant challenge in post-MD training system $(8,27)$. However, integrating these IMGs into the mainstream Canadian healthcare system might well be a viable strategy.

\section{Conclusions}

Canada's recruitment of IMGs is not considered active and hence is much less of an ethical concern. That does not imply Canada should continue passive recruitment to 'fill-in' the (rural) gap which is already shown to be ineffective in the long run. Canada should understand that whatever the recruitment process is, active or passive, it will have a deleterious impact on the healthcare system of the poorer 'donor' countries. But what is more important for Canada is to value its own interest; Canada's ethical concern should weigh much less as opposed to its own overarching interest at large (i.e., reducing reliance on IMGs by attaining self-sufficiency). Once Canada is selfsufficient with its 'own' physician workforce, the passive inmigration would eventually go down to a negligible level. It is, thus, imperative that Canada formulate a long-term policy addressing rural physician retention and need-based specialtywise distribution of physician along with a calculated increase in medical school enrolment.
Acknowledgements

The author acknowledges the financial support from Canadian Institutes of Health Research (CIHR) through a $\mathrm{PhD}$ Fellowship via Western Regional Training Centre for Health Services Research (WRTC). However, neither CIHR nor WRTC had any influence in conceptualizing, drafting, and/or publishing (or otherwise) this article. The author also acknowledges the contributions from Dr Steve Morgan and Cathy Chabot for their valuable inputs, suggestions and revisions throughout the manuscript writing process.

Ethical issues

Not applicable.

Competing interests

The author declares that he has no competing interests.

Author's contribution

$\mathrm{NI}$ is the single author of the manuscript.

\section{References}

1. Canadian Collaborative Centre for Physician Resources. Canadian Physician Resources - 2012 Basic Facts. Canadian Medical Association; 2012.

2. Esmail N. Canada's physician supply. Fraser Forum; 2008.

3. Esmail N. Canada's physician supply [internet]. Fraser Forum; 2011. Available from: http://www.fraserinstitute.org/ uploadedFiles/fraser-ca/Content/research-news/research/ articles/canadas-physician-supply.pdf

4. Statistics Canada. Access to a regular medical doctor, 2011 [internet]. 2011. Available from: http://www.statcan.gc.ca/pub/82625-x/2012001/article/11656-eng.htm

5. Canadian Institute for Health Information (CIHI). International Medical Graduates in Canada: 1972 to 2007. Canadian Institute for Health Information; 2009.

6. Phillips RL Jr, Petterson S, Fryer GE Jr, Rosser W. The Canadian contribution to the US physician workforce. CMAJ 2007; 176: 1083-7. doi: 10.1503/cmaj.060525

7. Roos NP, Gaumont M, Horne JM. The impact of the physician surplus on the distribution of physicians across Canada. Can Public Policy 1976; 2: 169-91. doi: 10.2307/3549205

8. Canadian Residency Matching Service. Canadian Students Studying Medicine Abroad 2010. Ottawa, ON: Canadian Residency Matching Service; 2010.

9. Canadian Institute for Health Information (CIHI). Supply, Distribution and Migration of Canadian Physicians, 2010. Ottawa, Ontario, Canada: Canadian Institute for Health Information; 2011.

10. McElroy R. Canada's shortage of physicians. Can Fam Physician 2004; 50: 349 .

11. Chan BTB. From perceived surplus to perceived shortage: what happened to Canada's physician workforce in the 1990s? Ontario: Canadian Institute for Health Information; 2002.

12. Fooks C, Duvalko K, Baranek P, Lamothe L, Rondeau K. Health human resource planning in Canada: Physician and nursing work force issues: Commission on the Future of Health Care in Canada. Ottawa, ON: Canadian Policy Research Networks Inc.; 2002.

13. Ethier J-L, Forté S. Canadian Medical Student Policy Statement on the Recruitment of International Medical Graduates by Canadian Provinces. Canadian Federation of Medical Students; 2008.

14. Busing N. Managing physician shortages: We are not doing enough. CMAJ 2007; 176: 1057. doi: 10.1503/cmaj.070258 
15. College of Physicians and Surgeons of Ontario (CPSO). Tackling the Doctor Shortage: A Discussion Paper [internet]. College of Physicians and Surgeons of Ontario; 2004. Available from: http:// www.cpso.on.ca/CPSO/media/uploadedfiles/policies/positions/ resourceinitiative/Doctor-shortage.pdf

16. Mullan F. The metrics of the physician brain drain. N Engl J Med 2005; 353: 1810-8. doi: 10.1056/nejmsa050004

17. Bourgeault IL, Baumann A. Ethical Recruitment and Integration of Internationally Educated Health Professionals in Canada. 2011. Available from: http://rcpsc.medical.org/publicpolicy/imwc/ Canada_Theme_Ethical_Integration_of_IEHP_Canadian_ Paper_Bourgeault_Baumann.pdf

18. Wright D, Flis N, Gupta M. The 'Brain Drain' of physicians: historical antecedents to an ethical debate, c. 1960-79. Philos Ethics Humanit Med 2008; 3: 24. doi: 10.1186/1747-5341-3-24

19. Mclntosh $\mathrm{T}$, Torgerson $\mathrm{R}$, Klassen $\mathrm{N}$. The ethical recruitment of internationally educated health professionals: lessons from abroad and options for Canada. Ottawa: Canadian Policy Research Networks; 2007.

20. Evans RG. Does Canada Have Too Many Doctors? Why Nobody Loves an Immigrant Physician. Can Public Policy 1976; 2: 14760. doi: $10.2307 / 3549203$
21. Taylor AL, Dhillon IS. The WHO Global Code of Practice on the International Recruitment of Health Personnel: the evolution of global health diplomacy. Global Health Governance 2011; 5 $1-24$.

22. Audas $R$, Ross $A$, Vardy $D$. The use of provisionally licensed international medical graduates in Canada. CMAJ 2005; 173: 1315-6. doi: 10.1503/cmaj.050675

23. Watson DE, McGrail KM. More doctors or better care? Healthc Policy 2009; 5: 26-31. Doi: 10.12927/hcpol.2009.21000

24. Frechette D, Hollenberg D, Shrichand A. What's really behind Canada's unemployed specialists? Too many, too few doctors? Findings from the Royal College's employment study. Ottawa, Ontario: The Royal College of Physicians and Surgeons of Canada; 2013.

25. Kapadia RK, McGrath BM. Medical school strategies to increase recruitment of rural-oriented physicians: the Canadian experience. Can J Rural Med 2011; 16: 13-9.

26. UK Department of Health. Code of practice for NHS employers involved in the international recruitment of healthcare professionals. London: UK Department of Health; 2001.

27. Sullivan P. Estimated 1500 Canadians studying medicine abroad. CMAJ 2007; 176: 1069-70. doi: 10.1503/cmaj.070328 